\title{
An Agent Oriented Business Model for E-Commerce based on the NYSE Specialist System
}

\author{
Kenneth Griggs, Ph.D. \\ Associate Professor \\ CalPoly \\ San Luis Obispo, CA 93407 \\ Tel: 805-756-2731 \\ Email: kgriggs@calpoly.edu
}

\begin{abstract}
The rapid development of commerce on the World Wide Web has been accompanied by the creation of new business models and customer relationships involving the use of intelligent software agents. Agents are characterized by autonomy, perception, and intelligence and have been used primarily for search and data mining activities on the Web. A parallel trend in electronic commerce is the development of auction markets in contrast to traditional fixed posted price models. Web based auction markets are structured on the "English Auction" model where a reserve price is established and bids are increased until the market is cleared.
\end{abstract}

This paper describes an intelligent agent based architecture for electronic commerce. The proposed architecture implements a continuous double auction modeled on the two hundred-year-old New York Stock Exchange specialist system. The complex functionality of the spccialist system is replicated through dedicated agents and knowledge bases that interact with buyer and seller agents. The specialist system, thought to be superior to other auction systems, requires a relatively high level of intelligence.

The proposed architecture fully models the duties of a human specialist at a NYSE stock exchange post. These duties are

\footnotetext{
Permission to make digital or hard copies of all or part of this work for personal or classroom use is granted without fee provided that copies are not made or distributed for profit or commercial advantage and that copies bear this notice and the full citation on the first pagc. To copy otherwise, to republish, to post on servers or to redistribute to lists, requires prior specific permission and/or a fee.

SIGCPR 2000 Evanston Illinois USA

Copyright ACM 2000 1-58113-212-x/00/04 ..\$5.00
}

broadly described as customer agent, principal, market catalyst, and auctioneer. In addition to describing the architecture, the paper includes a discussion of current research in electronic commerce auction markets and likely future impacts of the technology.

\section{KEYWORDS}

Agents, electronic commerce, auction markets

\section{INTRODUCTION}

The term "e-Commerce" is so new that an official spelling of the term has yet to appear. Indeed, a recent exploration of the term on the World Wide Web (hereinafter "the Web") revealed a variety of spellings including "eCommerce", "e-commerce",

"Ecommerce", "E-Commerce", "Ecommerce" and simply "EC". Although the name of the field cannot yet be spelled definitively. a number of important concepts have already emerged.

Much of the recent EC literature has been devoted to the identification of a set of trends that includes the creation of new business models and the broad use of network-centric software agents. A business model created by EC is the use of auction techniques in environments not normally characterized by auctions (such as retail sales). Auctions are conducted virtually in cyberspace and involve minimal customer contact. Instead, customer contact occurs through the use of software agents that represent the customer in the auction process. Buyer and seller agents interact and transactions are created between them according to customer instructions. Thus, the cognitive effort needed to engage in the auction is transferred to the agent. 
Auctions are complex and skill is required from both buyer and seller. In addition, auctions are associated with markets dominated by professional traders, such as the art, stock, currency, and commodities markets. Auction markets reveal the "market price" for goods. That is, a price derived from a free and open exchange between buyers and sellers.

The alternative to auctions, fixed posted pricing, is thought to have evolved in response to the complexity of auctions. Prior to the $18^{\text {th }}$ Century, auction markets predominated in all forms of commercial transactions [10]. Indeed, most retail transactions were handled by direct negotiations between buyers and sellers just as they remain in many countries today. $\Lambda$ retail transaction at a bazaar could be viewed as a form of auction since it normally involves price movement based on a fluctuating set of bid and ask prices. Thus, at the retail level, fixed prices are a relatively new phenomenon. Fixed prices do not require negotiation and the onus of pricing is on the seller. Also, from an informational standpoint a fixed price requires less effort since it is updated infrequently and once posted, is known to all buyers for a period of time. For most sellers, a profit-maximizing price is an elusive goal and, similarly, for most buyers, a fixed price requires research to establish its relative value. In a sense, both sides of the transaction are searching for a market price. A market price is a signal to buyers and sellers alike that represents an underlying value of a good in a competitive environment consisting of other buyers, sellers, and altemative goods. Thus, a market price is a valuable piece of information for both parties. In short, prior to EC, a market price established from an auction process (particularly for retail goods) simply required too much expertise and effort.

In EC, the use of intelligent software agents to reduce cognitive load and complexity has lead to a resurgence of interest in auction techniques. Buyer and seller agents are used to provide information, conduct negotiations, make bids, and manage virtual auctions. Currently, EC based auctions rely on relatively simple auction techniques that typically involve a single seller agent and multiple buyer agents with steadily increasing bids until the market clears. However, more sophisticated and powerful auction techniques are candidates for use in EC. The Continuous Double Auction (CDA) implemented via the specialist system at the New York Stock Exchange is of particular interest. The specialist system is used to manage a complex and dynamic trading environment and has proven merit over the two hundred years of its existence.

This paper describes an architecture that represents the intersection of the auction concepts embodied in the NYSE specialist system, recent developments in network-centric software agents developed from traditional $\mathrm{AI}$ techniques such as agents and knowledge bases (KBs), and trends in EC (Figure 1).

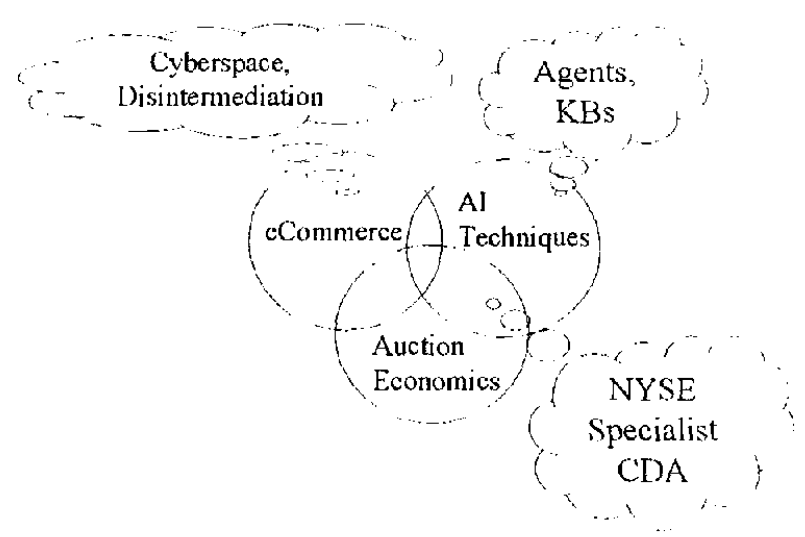

Figure 1: Origins of the Concept

In EC, transactions are conducted in a virtual electronic space (known as "Cyberspace") that is implemented in a distributed object environment. Transactions occur in the space with sottware agents that replace a human internediary. "Disintermediation" is an important emerging characteristic of EC.

\section{AUCTIONS}

Although auctions represcnt a pervasive, organized form of commercial activity, they have been studied very little until recently. The pioneering work of Smith, et al [11] in the empirical, laboratory based, investigation of auction markets is noteworthy in that it was an attempt to understand a broad range of market behaviors including crashes (a sudden collapse of prices) and bubbles (a sudden sharp increase in prices unrelated to fundamental value). In addition, Smith [11] and Cassidy [1] have empirically examined a variety of auction markets and have developed a set of auction market frameworks.

\subsection{Auction Formats}

A wide range of auction types has been used throughout history. However, the two most common forms of auction in use today are the "English" and "Dutch" varieties.

An English auction is characterized by the use of a "reserve" price or bid floor that is a price below which no bids will be accepted. An auctioneer guides the bidding process upward until a final, highest bid is accepted.

The Dutch auction originated with the I)utch flower market and is still in use today. It is the reverse of an English auction in that an auctioneer states a high starting price or price ceiling at the outset. The auctioneer proceeds to reduce the price by a fixed increment until a bid is made. "The first bid is taken.

English and Dutch auctions may contain one or more of the same goods or they may have a set of different goods for sale. Most art auctions are English such as those conducted by Sotheby's. 
Filenes's Bargain Bascment (in Boston) is an example of a Dutch auction in the sense that prices are reduced by a fixed percentage over time.

A third type of auction is known as the Continuous Double Auction (CDA) and is the form of auction used to trade stocks on the New York Stock Exchange. A CDA is typified by a price that dynamically fluctuates aver time based on competitive bidding on a trading floor. Buyers and sellers assemble and engage in open outcry statements of their bids and asking prices. The process is managed by a specialist auctioneer who has a complex set of motivations and responsibilities for the maintenance of an orderly and fair market.

\section{2 The Role of The Specialist In The Continuous Double} Auction at The New York Stock Exchange (NYSE) NYSE specialists are employees or partners of independent specialist firms that are charged with the management of trading in the shares of certain firms. There are 33 firms employing approximately 460 specialists who specialize in more than 3,000 stocks [9]. In this capacity, they are governed by a complex set of rules that determine their behavior. Figure 2 shows an example of a trading post on the floor of the exchange

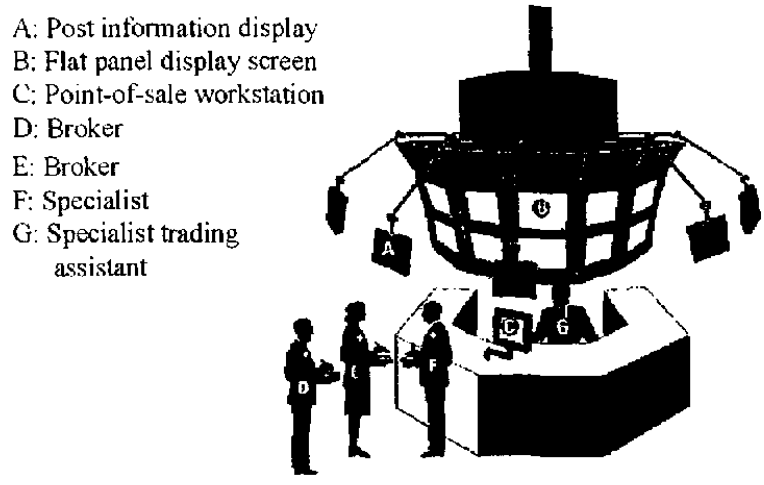

Figure 2: A Trading Post at the New York Stock Exchange Courtesy: New York Stock Exchange

The specialist, labeled $\mathrm{F}$ in the illustration, stands in front of the post and interacts directly with "Floor Brokers", labeled D and E, who are agents of various brokerage firms. They execute buy and sell orders on behalf of their customers. A trading assistant, labeled $\mathrm{G}$, as well as information displays and transaction terminals surrounding the post $(A, B, C)$ assist the specialist.

Floor brokers gather in front of the trading post and indicate their trading positions to the specialist by open outcry and hand signal Trading positions consist of bid prices, ask prices and share amounts. Trading at the NYSE has its own vocabulary with the following basic elements:
1. Bid - an offer to buy a fixed number of shares at a lixed price

2. Ask - an offer to sell buy a fixed number of shares at a fixed price

3. Current Market Price - the lowest asking price and the highest bid price currently available

4. The Spread - the difference between a bid and ask price

5. Market urder - an offer to buy or sell a lixed number of shares at the Current Market Price

6. Limit Order - an offer to buy or sell shares at a price which is currently out of the market (ask above current asking price, bid below current bid price)

7. Specialist's Book - an order status system which displays the status of all types of orders(Current Market, Market Orders, and Limit Orders)

8. The tape - a ticker tape display system which informs all market participants of the market status of all stocks (last trade, change from last closing price, amount, bid, ask, time, etc).

9. Short Sale - the sale of a stock not owned by the seller

In the application of the contimuous double auction (CI)A) of the NYSE, the specialist has four primary functions [9]:
Agent
The specialist may act as broker and buy and sell shares as a customer agent. The specialist collects a commission from the transaction. The use of a specialist, in contrast to a regular broker, benetits the customer who has a large share block and desires anonymity.

\begin{abstract}
Auctioneer
The specialist's role is to manage the auction in an orderly, efficient, competitive, and fair fashion. To do so, the specialist risks his own capital in the process. The specialist is charged with adding liquidity to the market and is a buyer and seller of last resort and is required to trade against the trend to cushion sharp market movements. For example, in a rapidly declining market in which there are no buyers at the current making bids and consequent trades at progressively downward levels. In the opposite case, where there are no sellers of a stock, the specialist must sell stock even if the stock is not in his inventory (execute a short sale) Thus, the specialist bridges temporary gaps in supply and demand and strives to guarantee that stock is available for sale or purchase at an expected price. The specialist attempts to keep the spread as narrow as possible and can halt trading under certain market
\end{abstract} market price, the specialist will "gap down" the price by 
conditions or when news is pending. The specialist is responsible for placing all trades on the tape, managing his own stock inventory, and determining share prices at the open of the market.

\section{Catalyst}

The specialist keeps track of all known interest in a stock and alerts interested buyers and sellers of market conditions when appropriate. By giving updates to a previously interested party, a specialist helps trades occur where they otherwise might not happen. In this role the specialist may promote his own principal function.

\section{Principal}

The specialist can buy and sell for his own account. However, specialists are required to place and execute all customer orders ahead of their own. The specialist is a uniquely qualified trader that can trade intelligently based on a knowledge of the specialists book [2] [4]. Thus, the specialist has a complete picture of the market that is not publicly available (except when revealed to floor brokers on an "as requested" basis). In addition, the specialist "rounds out" orders from his inventory. For example, to complete a sale of 1000 shares at $\$ 11.00$ when there are only buyers for 800 shares at this price, the specialist will buy the marginal 200 shares.

The specialist system is unique in that it offers a full range of market support not found in other auction market models.

\subsection{The Specialist's Book}

Integral to the specialist system is a central repository of order status data known as the "Spccialist's Book". The "book" portion of the term refers to the historical use of a ledger book to record market order status. Figure 3 is a very simplified view of the inajor components of the book

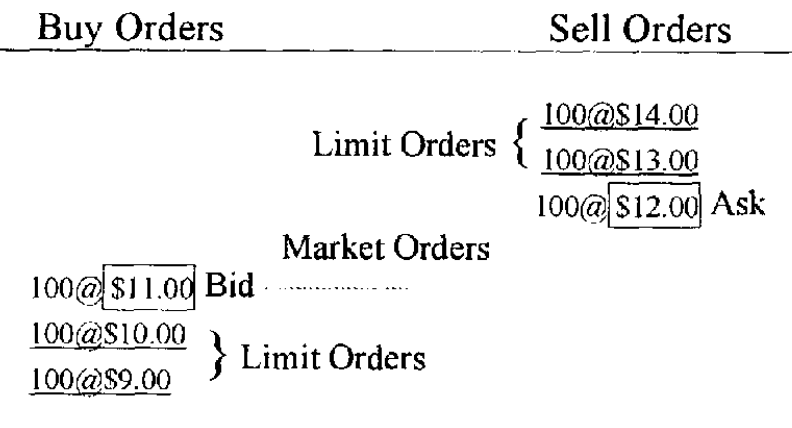

Figure 3: A Simplified View of the Specialists Book

In the example shown in Figure 3, the current market price of a stock is $\$ 11.00 \mathrm{Bid} / \$ 12: 00$ Ask. This means that a buyer will pay at most $\$ 12.00$ for 100 shares and a seller will receive at least $\$ 11.00$ for a one hundred-share order. The spread is $\$ 1.00$ (the difference between the bid and ask price). The specialist attempts to keep the spread to a minimum by filling buy or sell orders himself that are within spread (e.g., \$11.50). These transactions are subject to a set of rules whose intent is to guarantee that no customer is disadvantaged by the transaction. The market is said to be "improved" since an order has been filled and the specialist has gone against the trend (a bid higher than the current bid, a sale lower than the current ask). In short, the specialist has bought/sold at a higher/lower price than the current market. In addition, the spread will be narrowed by $\$ .50$. That is, the new bid or ask price will be set to $\$ 11.50$

The specialist's book is an important concept since it is the primary repository of market information required to perfonn the specialist functions.

\section{INTELLIGENT SOFTWARE AGENTS}

Soltware agents have an ancestry within the AI community that is over twenty five years old. A number of rescarchers at Xerox PARC, [3], MIT [7], [8] and at other places developed the concept. Agents are software entities that have the following characteristics $[13][6]$ :

1. Autonomy - agents can operate without the direct intervention of humans or others

2. Social ability - agents can interact with other agents and/or humans

3. Reactivity-agents perceive their environment and respond in a timely fashion to changes that occur in it

4. Pro-activeness - agents can exhibit goal-directed behavior by taking the initiative

5. Mobility - agents can move to other environments

6. Temporal continuity - agents are continuously running processes

From an application standpoint, agents evolved from a series of developments in networks, operaling systems, and computer languages. These include remote procedure calls, background processes, and object technology. Some have speculated that agents represent a new paradigm in information systems development [5] and are likely to be the framework for all new computing environments in the next century. Agents may be viewed as forming the transition from direct manipulation (as in traditional applications and direct manipulation interfaces) to indirect manipulation. 


\subsection{E-Commerce (EC) Agent Examples}

Currently, in EC, agents are employed in a fairly narrow domain consisting of search, retrieval, collaborative filtering, and interface assistants. Tablel shows a few examples of current EC agents.

\begin{tabular}{|l|l|}
\hline Agent & Description \\
\hline Hotbot & $\begin{array}{l}\text { Large collection of agents on the web used to } \\
\text { extract material from meta tags in home } \\
\text { pages as well as navigating through web site } \\
\text { links to gather keywords. Reports keywords } \\
\text { back to an index engine }\end{array}$ \\
\hline Excite & $\begin{array}{l}\text { Uses agents to gather relevant keywords and } \\
\text { applies a statistical frequency of occurrence } \\
\text { technique for concept based searching }\end{array}$ \\
\hline Office Assistant & $\begin{array}{l}\text { Background process that tracks usage of } \\
\text { Microsoft applications and makes help } \\
\text { recommendations. Used as the basis for a } \\
\text { Microsoft Agent framework }\end{array}$ \\
\hline Elf & $\begin{array}{l}\text { Proxy bidder used by eBay that dynamically } \\
\text { bids in a predefined range against other } \\
\text { bidders }\end{array}$ \\
\hline BookMatcher & $\begin{array}{l}\text { Used by Amazon.com to make book } \\
\text { recommendations to customers based on a } \\
\text { collaborative filtering technique. Agents act } \\
\text { in parallel to build communities of user } \\
\text { preferences based on past customer } \\
\text { purchases. }\end{array}$ \\
\hline
\end{tabular}

Table 1: Examples of Agents Currently Employed in eCommerce

Although diflicult to measure precisely, it could be assumed that the growth rate of the use of agent technology on the Internet roughly approximates the growth of the Internet itself. Figure 4 [12] shows the growth of domain hosts from 1991 to 1998. This is an exponential growth curve with domain hosts doubling about every year.

\section{Internet Domain Survey Host Count}

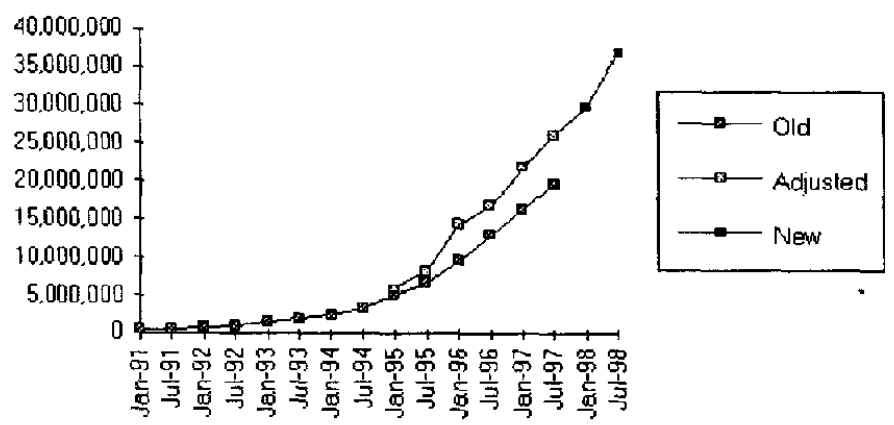

Figure 4: Growth of Internet Domains (1991 - 1998)

\section{Courtesy of Network Wizards}

The adjusted and new line segments are based on revised data gathering techniques and are deemed more accurate than old measurements.

\section{PROPOSED ARCHITECTURE}

Since the use of software agents in support of EC auctions is comparatively new, it is understandable that relatively straightforward auction techniques would be employed, namelv, English and Dutch auctions. As previously discussed the NYSE. Specialist system is significantly more complex in that it is involved in every important function of the process. The evolution of the specialist system can be viewed as an attempt to solve the principal/agency problem in market making. The system is a response to the need to have an institution whose individual goals are aligned with the need to create an orderly and liquid market. Specialist behavior is subject to a set of rules whose purpose is to guarantee that he/she acts in the best interests of the market and, as such, is not placed at a tinancial disadvantage. Specialist earnings come from commissions and trading prolits. Although trading profits come from insider knowledge of the specialist book, this is information about the market as a whole and not specific company news. Hence, it is not "insider trading" in a legal sense.

A specialist software agency architecture is proposed that would mimic the type of specialist behavior and responsibilities found at the NYSE. Figure 5 shows a high level view of a CIIA market handled by a software agency. An "agency" is a collection of agents that would form a kind of electronic trading post. Buyer and seller agents make their bids and offers known to the specialist agency and the agency guides the market. Note that in the NYSE buyers and sellers may make trades with themselves without using the specialist. However, such trades are given to the specialist to put on the stock ticker. This is also true in the proposed architecture. 


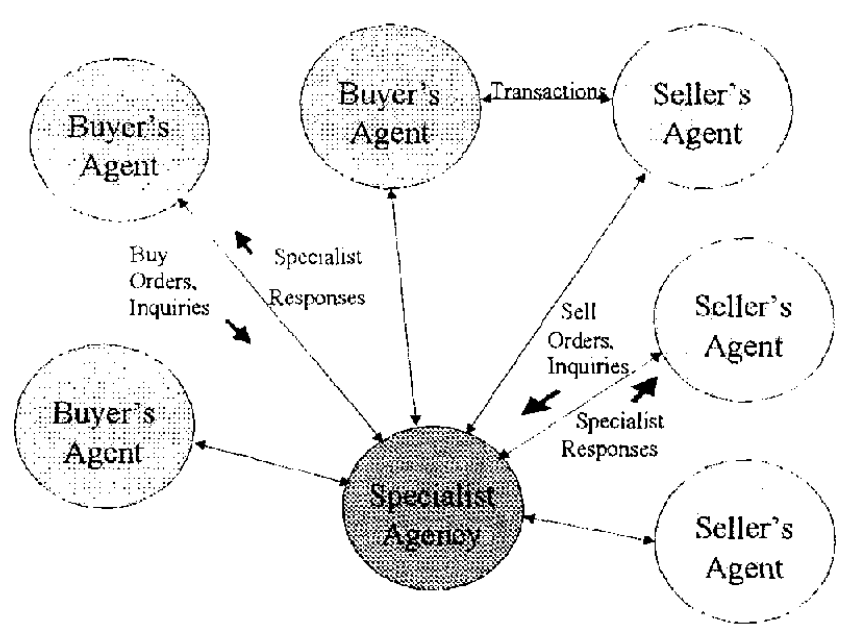

Figure 5: An Agent Based Trading Post

Figure 6 is an exploded view of the proposed architecture. The agency has four agents who each represent the four functions of the NYSE specialist, namely, auctioneer (trading agent), customer agent, (representation agent) principal (principal agent), and market catalyst (notification agent).

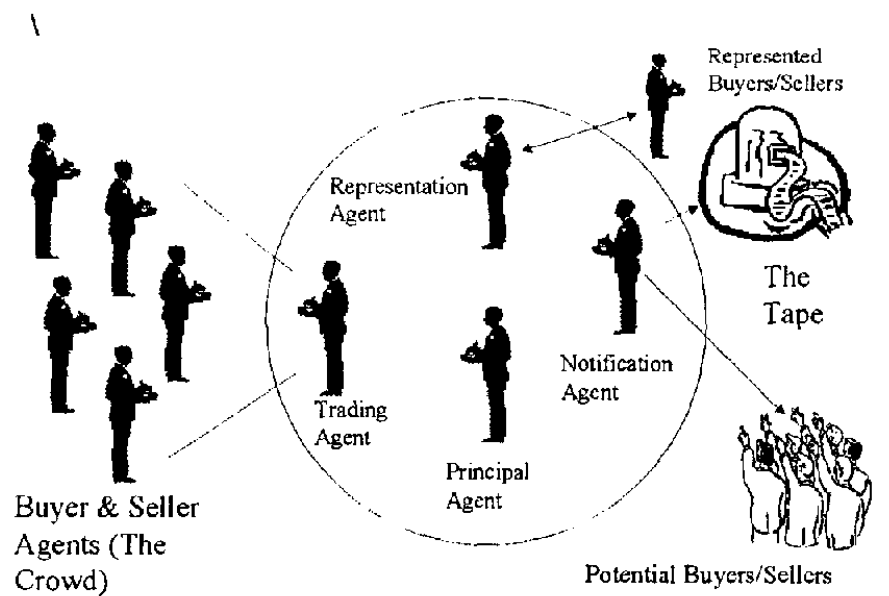

Figure 6: An Exploded View of a Specialist Agency

The encapsulation of specialist behavior and intelligence in a software agent requires a set of knowledge bases to represent specialist knowledge, a set of databases containing market and transaction data, and an intercommunication method between specialist functions. Figure 7 shows a detailed view of a multiple agent architecture that uses the four specialist functions described by the NYSE as a foundation.

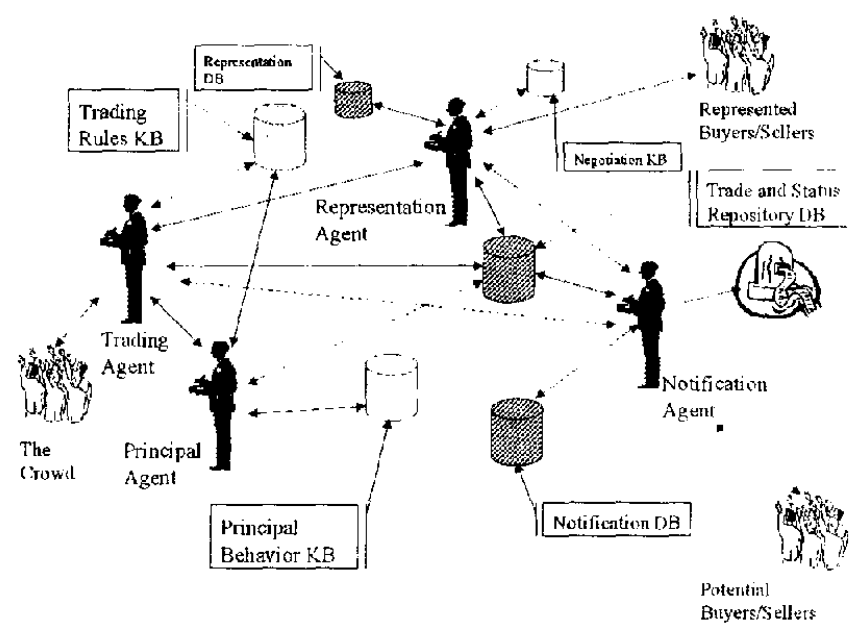

Figure 7: Detailed View of the Proposed Architecture

\subsection{Agents}

The four agents act independently and communicate with each other when required. The functions of the agents are described as follows-

\section{Trading Agent (NYSE Auctioneer function)}

- Invokes trading rules

- Matches orders

- Maintains Bid/Ask sprcad

- Records transactions to the tape

- Updates inventory

- Notifies other agents when required

- Records direct buyer-seller trades

Principal Agent (NYSE Principal function)

- Performs an analysis using data from the trade repository

- Invokes principal behavior rules

- Requests trades from the trading agent

\section{Notification Agent (NYSE Catalyst function)}

- Notifies possible buyers and sellers of market conditions

- Maintains and updates the notification IDB and the tape

- Requests trades from the trading agent

- Notifies the representation agent when applicable

\section{Representation Agent (NYSE Agent function)}

- Interacts with represented buyers \& sellers

- Requests trades from the trading agent

- Negotiates commissions

- Updates trade repository 
In addition to the four agents, the architecture requires a set of knowledge bases and databases as follows-

\subsection{Databases}

Notification

Contains names and interest information on potential buyers/sellers (i.e., email address, item of interest information, mailing address, ctc.)

Trade \& Status Repository

The central store for all market activity.

Contains all of the specialist's book information, archived trades, current bid/ask information, address information for trade reconciliations, etc

Representation

A small database that contains address information on buyers and sellers represented by the specialist agency, commission information, and pointers to order status in the Trade \& Status Repository

\subsection{Knowledge Bases}

\section{Trading Rules}

A rule based expert system that contains rules that determine allowable trading behavior. At the NYSE, these rules are contained in a two hundred-page document that determines, for example, when a specialist is allowed to trade for his/her own account.

\section{Principal Behavior}

A rule-based expert system and/or a neural net application that determines trading opportunities and risks and advises on trade timing.

\section{Negotiation}

A small rule-based expert system that guides negotiation behavior for the representation agent based on a standard commission schedule, an estimation of the amount of effort required to represent a buyer or seller, and related factors.

\subsection{Issues in the Architecture}

This architecture is inherently complex since it is a model of an auction process (the CDA) and a system that relies primarily on human judgement (the NYSE Specialist System). Furthermore, although the concept of intelligent agents and agencies has existed for some time, implementation of truly intelligent agents has lagged. The following are issues in the architecture that have to be addressed if it were to implemented-

- Consistent agent \& market semantics

- A deeper understanding of specialist knowledge and functions (process model)

- Agent development tools

- A high level agent scripting language

- An analysis of knowledge representation techniques to be used by the agents (rule-based ES shell, neural net, genetic algorithm, etc.)

\section{Conclusion}

This paper proposes an architecture for auction based electronic commerce based on the NYSE specialist system. The architecturs uses a collection of agents to accomplish the specialist functions. Commercial applications and ongoing research in English and Dutch auctions have proved the viability of the use of agents in simple market structures. In addition, agents have been successfully employed on the Web in other capacitics. Because of the intelligence requirements and inherent complexity of the continuous double auction with a specialist, no research or commercial applications have, as yet, been undertaken. The proposed architecture is a first attempt at an examination of the functional requirements of a CDA/Specialist system. The architecture replicates NSYE specialist functionality through agent interaction and specialized knowledge and databases. However, an experimental implementation of the architecture awaits further development in agent technology as well as a deeper understanding of specialist knowledge, behavior, and the rules under which the specialist works. 


\section{References}

[1] Ralph Cassady, Jr., Auctions and Auctioneering, University of California Press, Berkeley and Los Angeles, 1967

(2) NYSE Working Paper, Abstract 92-03 The Trades of Market Makers: An Empirical Analysis of NYSE Specialists by Joel Hasbrouck; Gcorge Sotianos Published in The Journal of Finance. Available at

http//www.nyse.com/public/thenyse/le/leix.htm

[3] Kay, Alan (1984): Computer Software. Scientific American 251(3, September), 53-59

[4] NYSE Working Paper, Abstract 94-01 Auction and Dealer Markets: An Empirical Analysis of NYSE Specialist Trading by Ananth Madhavan; George Sofianos, Available at http//www.nyse.com/public/thenyse/le/leix.htm

(5) Pattie Maes. Agents that reduce work and information overload. Communications of the ACM, 37(7), July 1994.

[6] Maes, P., Guttman, R., and Moukas, A., "The Role of Agents as Mediators in Electronic Commerce." Special Issue of Knowledge Engineering Review on Practical Applications of Agents, Edited by Barry Crabtree, to appear summer 1998
[7] Minsky, Marvin, The Society of Mind, Heinemann, London, 1987

18] Negroponte, Nicholas (1990): Hospital Comers. In: The Art of Human-Computer Interface Design. (Ed: Laurel, Brenda)

Addison-Wesley, Reading, Massachusetts, 347-353.

[9] 1997 Fact Book, New York Stock Exchange, Publications Department, 11 Wall St. New York, NY 1000

[10] Charles Smith, Auctions, the Social Construction of Value, Free Press, New York, 1989.

[1I] Experimental economics / edited by Vernon L. Smith Aldershot, Hants, England : E. Elgar; Brookfield, Vt., USA (rower Pub. Co., c1989

[12] Network Wizards, Amual Domain Host Survey, PO Bon 34.; Menlo P'ark, CA 94026

[13] M. J. Wooldridge and N. R. Jennings, (1995). Intelligent Agents: Theory and Practice, The Knowledge Engineering Review 10(2) 115-152 